\title{
The Value of User Participation in E-Commerce Systems Development
}

\author{
Julian Terry and Craig Standing \\ Edith Cowan University, Perth, Australia
}

\author{
j.terry@ecu.edu.au c.standing@ecu.edu.au
}

\begin{abstract}
Many researchers and practitioners consider user participation in the development of an information system is essential to the success of the system. System designers have promoted development techniques that demand user participation, such as prototyping, rapid application development and joint application design. Interestingly, the research literature on the topic has not been conclusive about the value of user participation, although the perception of value has still existed. The importance of user participation in information systems could be seen as a myth.

The time pressure to develop Web based e-commerce systems and the propagation of the view that e-commerce is different and subject to different rules has led developers to question the value of customer participation in the development process. Indeed, the notion of the "user" has become confused. No longer is a user necessarily found in-house, but may be a geographically remote customer unknown to an organization.

This paper proposes and validates a model that examines the role of key users and stakeholders in e-commerce applications development. Despite the business need for remote, untrained users to quickly feel comfortable and satisfied in an e-commerce site encounter, it appears that many organisations are making little effort to engage users in e-commerce site developmental activities.
\end{abstract}

Keywords: electronic commerce, systems development, user participation

\section{Introduction}

Since the 1960s, it has been generally acknowledged that user participation in the Information Systems (IS) development process increases the likelihood of project success (Barki \& Hartwick, 1994; Foster \& Franz, 1999). Put another way, lack of communication between users and developers has been a common theme in the well-documented reasons for failures in IS implementations (Bussen \& Myers, 1997). User involvement is likely to result in increased user satisfaction (Garceau, Jancura, \& Kneiss, 1993), and the perceived usefulness of the application (Foster \& Franz, 1999; Franz \& Robey, 1986;

Material published as part of this journal, either online or in print, is copyrighted by the publisher of Informing Science. Permission to make digital or paper copy of part or all of these works for personal or classroom use is granted without fee provided that the copies are not made or distributed for profit or commercial advantage AND that copies 1) bear this notice in full and 2) give the full citation on the first page. It is permissible to abstract these works so long as credit is given. To copy in all other cases or to republish or to post on a server or to redistribute to lists requires specific permission and payment of a fee. Contact Editor@inform.nu to request redistribution permission. McKeen, Guimarares, \& Wetherbe, 1994). Foster and Franz (1999, p.345) emphasise the need for user involvement, most importantly in the early stages of development, concluding, "Managers should actively seek user involvement in systems development activities.”

The portfolio of applications being developed today has changed with the

The original version of this paper was published as one of the 24 "best" papers in the proceedings of the 2003 Informing Science and IT Education Conference in Pori, Finland http://2003.insite.nu 
emergence of the E-Commerce (EC) business paradigm. Organisations are capitalising on the potential of new technologies such as the Internet, Intranets and the World Wide Web to improve transaction efficiency, reduce operation costs and increase market share. This paradigm shift in business has been supported by applications with a different focus. While organizations continue to implement IS for internal use and to integrate with known business partners, the focus of this paper is business-to-consumer e-commerce (B2C) applications that are available for universal use.

The literature to date regarding user participation in IS development has not differentiated between applications designed for traditional internal environments or for B2C e-commerce applications. In comparing the two domains Fraternali (1999, p. 227) states:

"Applications for the Internet in such domains as electronic commerce, digital libraries and distance learning are characterized by an unprecedented mix of features that makes them radically different from previous applications of information technology".

However the underlying process for developing applications is addressed by Yourdon (2000), who questions whether e-business/Internet projects are really that different by suggesting Ebusiness projects face the same demands pressures and risks as any other kind of IT development project, but to a greater degree. This added pressure comes from not only squeezed timeframes for delivery, but also from the necessity to change accompanying business processes. He suggests also that the e-business phenomenon is much more fundamental because it creates a much more intimate connection with customers, vendors and suppliers.

One feature of B2C systems that differentiates them from traditional MIS applications is the identity of the "user". Traditional internally focused information systems are developed for a clearly defined set of known users, either in-house or business partners. The development may be undertaken in-house or by external parties, but either way, the user community is clearly identifiable. They are often championing the project and possibly funding it from their budget. Likewise offthe-shelf packages allow organisations to see what they are getting before software purchase. Customisation of the package to meet the organisation's needs can then precede implementation. Again the known, distinguishable in-house user community is able to be involved in decisions regarding the adoption and adaptation of the product.

In the global business environment of today, a B2C application is inviting the consideration of the world at large. Rather than serving a known user group, B2C Web sites may target the world at large. Potential users are diverse in all respects, ethnically, culturally as well as geographically. They are also diverse in their ability to use computers.

This paper investigates the extent and relevance of user involvement in B2C IS developments. Three organisations involved in substantial B2C developments were studied, with particular emphasis on the role of users throughout the development lifecycle, and a multi-perspective view of the success of the system. The perspectives are those of the business sponsor of the EC development, the project leader, internal users of the application and external customers. The results from these cases are presented and then discussed.

\section{Users and User Involvement}

The term "user" is open to ambiguity. Land and Hirschheim (1983) acknowledge the existence of different types of users: senior management who bear ultimate responsibility for the organisation's well-being and who may use outputs of IS developments; middle management who are responsible for the operational staff using the IS; and finally those staff who regularly interact with the system. From project conception, through the development lifecycle each of these users may contribute or participate in IS development activities. The term "user" is not generally defined 
specifically in the many studies published in literature, beyond the Ives and Olson (1984, p. 587) definition of them as "representatives of the target user group".

User involvement has traditionally been referred to as participation in the system development process measured as a set of activities that users or their representatives have performed (Baroudi, Olson, \& Ives, 1986; Doll \& Torkzadeh, 1989; Ives \& Olsen, 1984). Barki and Hartwick (1994, p. 60) proposed a clearer definition for user involvement, distinguishing it from user participation as in other disciplines. They define user participation as "the assignments, activities and behaviours that users or their representatives perform during the systems development process." User involvement refers to the "subjective psychological state reflecting the importance and personal relevance that a user attaches to a given system." These definitions appear to have been generally accepted in the ensuing literature (Hunton \& Beeler, 1997; McKeen \& Guimaraes, 1997) as they are in this paper.

The literature has not found the identity of the users or their representatives to be a contentious point. Often all of the three user types above are domiciled in the same workplace and are identifiable to IS development project managers. Their participation in for example, problem definition, specification of requirements, design and testing could be mandated within the organisation. So the users involved in IS projects are clearly identifiable to practitioners and to researchers.

Identifying the user community in B2C systems development is more difficult. Another user type has emerged. B2C transactions involve remote customers who may not be known to the organisation. They are the ultimate end-users, but are beyond the accepted definition of users above. They are not staff and do not fall under the control structures of the organisation. Business success is based on their acceptance and usage of the system. Their participation cannot be mandated and involvement (psychological engagement) or attitudinal disposition to the system cannot be taken for granted. We will call this group of users “customer-users”.

\section{User Satisfaction}

While there is no direct measure for the success of an Information System, (see DeLone \& McLean, 1992), empirical researchers have commonly used user satisfaction as the dependent variable (Doll \& Torkzadeh, 1990; Franz \& Robey, 1986; McKeen \& Guimaraes, 1997; Powers \& Dickson, 1973). Prominent among the independent variables studied for their influence on this measure are user involvement or participation in the system development process (see Barki \& Hartwick, 1994).

Although the efficacy of user involvement in information systems development leading to system success has been the subject of much research, it has not been studied in the context of B2C systems development. However, the concept of system success as measured by user satisfaction may be more relevant to B2C developments than to traditional systems. With no compulsion to visit and interact with a site, an Internet user needs to feel comfortable with a site's usability - and quickly. If not, they can and do take their trade to another site. Shopping cart abandonment rates of 20 to 60 percent per transaction, reported by Schwarz (2001), is testament to dissatisfied customers.

It has been said that there is only one chance to make a first impression. In the Internet world it may be better to have no site than an unintuitive one that is unlikely to be revisited. Furthermore customer-users are not availed of the training in application use that traditional system users expect. User support is also not likely to be as readily available. So there is a need for EC developers to be particularly sensitive to usability issues. However, user satisfaction is only one measure of system success and other user groups or stakeholders such as business sponsors would have different views that may emphasise the business case. 


\section{Research Methodology}

The research questions are taken from the model (Figure 1) and are used in this study as a method for determining the extent and significance of user involvement on the success of EC applications. The research method takes a mini-case approach (Yin, 1994). A mini-case approach using purposive sampling was used since the organisations were required to exhibit the following characteristics (Silverman, 2000):

- Medium to large organisations that had distinct organisational boundaries and responsibilities that represented the variety of stakeholders;

- Organisations that had recently developed or substantially upgraded an EC application of a transactional nature.

The research model is shown in Figure 1. Many potential factors may influence the relationship between user participation and system success. Tait and Vessey (1988) described the need to reduce the number of factors being studied:

Rather than attempting to investigate all factors affecting user involvement and its impact on systems success, the model provides a structure within which to examine constructs central to influence of user involvement on system success.

Two contingent variables have been selected for this study, resource constraints and system impact. These are perceived to be particularly relevant to EC developments. (Terry \& Standing, 2001) in an exploratory study found that EC projects appeared to be particularly time-constrained. The extent of impact of the system is also particularly relevant to EC developments due to the need to adapt the business model to one that supports a non-traditional way of doing business. It has been suggested that EC implementations have failed because of the inappropriateness of the business model to support the impact of EC (Porter, 2001).

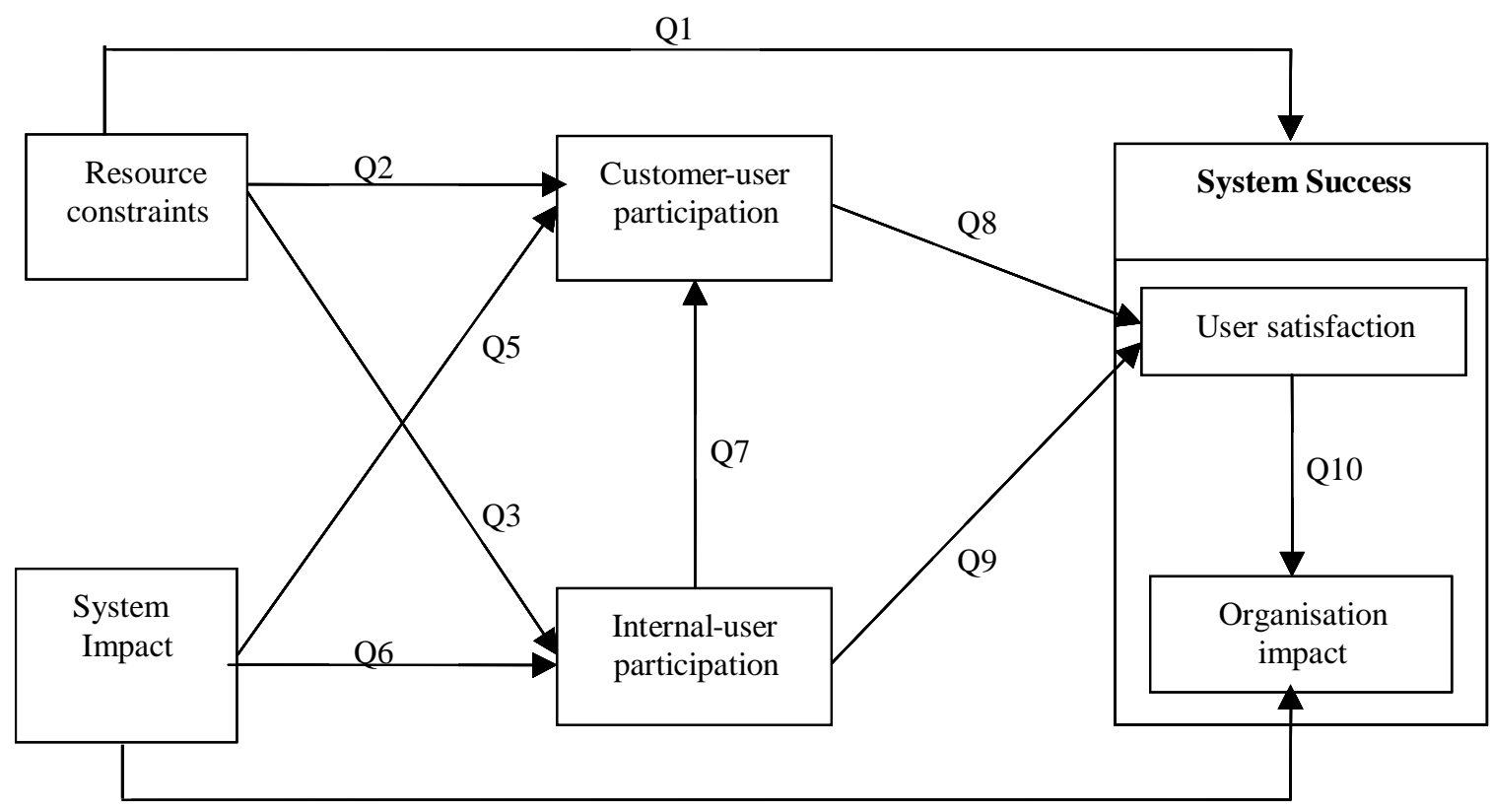

Q4

Figure 1: A Model for Assessing the Impact of User Participation on System Success 
The relationship between customer-user participation in EC system development and system success is the central focus of this paper. This relationship has been ignored in the academic literature to date; it is beyond the scope of the generally accepted definition of "user participation". The link between internal-user participation in EC system development and system success is equivalent to a typical MIS systems development project. In this situation the users of the system are internal to the organisation and are assumed to be able to be available to participate in activities throughout the development lifecycle.

System success is measured by both sets of users as user satisfaction, and also by the business sponsor in terms of organisational impact.

The research questions based on the issues from the literature are as follows:

- Q1. Will constrained resourcing impact the likelihood of EC system success?

- Q2. Will constrained resourcing affect the likelihood of customer-user participation in EC development?

- Q3. Will constrained resourcing affect the likelihood of internal-user participation in EC development?

- Q4. How does the impact of the EC system on the organisation affect its likelihood of success?

- Q5. How does the impact of the EC system on the organisation affect the likelihood of customer-user participation in the EC development?

- Q6. How does the impact of the EC system on the organisation affect the likelihood of internal-user participation in the EC development?

- Q7. Is there greater participation in EC development by internal-users or customer-users?

- Q8. Does customer-user participation have a positive effect on system success?

- Q9. Does internal-user participation have a positive effect on system success?

- Q10. What is the relationship between system success as measured by user satisfaction and organisation impact?

Three organisations were selected, each based in Perth, Western Australia. For each organisation, the perspectives of key stakeholders as well as users were surveyed by the completion of a focused questionnaire. These targets of the data collection were:

- The business sponsor. This is the person who has accepted the business case for the investment in the EC development.

- The project leader. This individual has been responsible for the development of the EC application and can respond to questions regarding the developmental process.

- The internal-user perspective. This is essentially the traditional in-house user of the application.

The customer-user perspective. This is the business target of the EC application and the user at whom the external interface is directed. 
Table 1: Data collection sources

\begin{tabular}{|l|c|c|c|c|c|}
\hline & $\begin{array}{c}\text { System } \\
\text { impact }\end{array}$ & $\begin{array}{c}\text { Resource } \\
\text { constraints }\end{array}$ & $\begin{array}{c}\text { Internal-user } \\
\text { participation }\end{array}$ & $\begin{array}{c}\text { Customer-user } \\
\text { participation }\end{array}$ & $\begin{array}{c}\text { System } \\
\text { success }\end{array}$ \\
\hline Business sponsor & & & & & $\mathrm{X}$ \\
\hline Project leader & $\mathrm{X}$ & $\mathrm{X}$ & & $\mathrm{X}$ & \\
\hline Internal users & & & $\mathrm{X}$ & & $\mathrm{X}$ \\
\hline Customer users & & & & & $\mathrm{X}$ \\
\hline
\end{tabular}

Four separate questionnaires were developed for the stakeholders/users. Table 1 shows the stakeholders/users and the focus of the survey questions directed to them. To be consistent with previous studies, where appropriate, the questionnaire design was adapted from earlier studies in the area. The business sponsor questionnaire was developed and validated by Mirani and Lederer (1998). It assesses system success through organisational impact. It reviews the three dimensions of the impact of an IS project on organisational performance: the strategic dimension, the informational dimension and the transactional dimension. The project leader questionnaire was a compilation of questions regarding:

- System impact or expected change brought about by the system. Three questions were derived from Anderson (1985).

- Resource constraints that may limit the effectiveness of the development process. Five potential constraints were derived from Tait and Vessey (1988), Doll (1987) and Terry and Standing (2001).

- External-user participation in the EC development process. This contained twelve multidimensional questions pertaining to potential areas for inclusion of customer-user input throughout the development process ie. Requirements gathering, design, usability testing, beta testing, post-implementation review and metrics generation.

The customer-user questionnaire addresses user satisfaction to measure system success. Measuring web site quality from the customer viewpoint has received little attention in the academic literature. It is clear that previous measures of user satisfaction are inadequate when taken from the traditional user in the MIS environment. For example, in a popular short-form measure of user satisfaction (Baroudi \& Orlikowski 1988), four of the thirteen questions are to do with the relationship between the user and the EDP staff. This relationship is expected to exist for an internal user but not an external one. A further two questions relate to systems development activities that, again, are beyond the scope of a party external to the organisation. An unpublished paper built on the Ph.D dissertation of Eleanor Loiacono (Loiacono, Watson, \& Goodhue, n. d.) uses a survey instrument of 36 questions The research draws on marketing literature as well as IS success literature to develop questions that are based on the concepts of usefulness, ease of use, entertainment and complementary relationship. In another unpublished paper, Barnes and Vigden (n. d.) describe the development, testing and validation of an instrument "WebQual" for assessing EC quality. This instrument uses 23 questions to survey EC site users online based on three areas: website usability, information quality and interaction quality. Except for the areas of entertainment and complementary relationship (Loiacono, Watson \& Goodhue, n. d.), there is a high level of correspondence between these two survey instruments. For this study the Barnes and Vigden survey instrument was selected for its clarity and relative brevity.

The internal-user questionnaire addresses internal-user participation in the EC development and satisfaction with the internal view of the delivered system. The literature identifies several instruments for data collection on user participation. The Doll and Torkzedah (1990) instrument consists of 8 questions relating to IS development activities. Each question is answered on a five point Likert scale in two ways: (1) the actual amount of time a user spent on the activity, and (2) 
the amount of time a user wanted to spend on the activity. The brevity of the instrument however means that the categories are very broad. Cote and Buckley (1987) contend that to be reported accurately the questions need to be specific and related to observable events, rather than rely on generalised opinions that can be biased. To that end, questions covering a wide range of potential participatory activities and behaviours should produce more reliable results (Barki \& Hartwick 1994).

Olson and Ives (1980) developed an instrument with 44 questions spread over the areas of system definition, physical design, implementation and general control. This instrument was refined by McKeen, Guimaraes and Wetherbe (1994).

Many studies have assessed the extent of internal user participation in systems development, although these have related to typical MIS application systems development projects. The application type however is not relevant to the nature of user participation in system development processes. The survey instrument is used and described by McKeen et al. (1994). It consists of 23 questions relating to participative behaviour throughout systems definition, systems design and implementation. Each question requires a dichotomous (yes/no) response indicating whether or not the particular participative behaviour was affected.

For comparative purposes, the internal-user questions regarding user satisfaction working with the installed application are a subset of those directed at the customer-users. The questions on user satisfaction and information quality are generic to using any software interface, and are retained. Those labelled "interaction quality" are clearly aimed at an external customer of an EC site, and are omitted.

The mini-cases were completed over a six-month period and the data analysed on a case-by-case approach relating the responses directly to the research questions. In the following reporting of the findings each component of Figure 1 is examined in turn.

\section{CASE 1. A High Profile Organisation Specialising in Online and Print Classified Advertising}

The site is a major outsourced redevelopment of a Web site, implemented within the last six months.

\section{Organisational impact}

Strategic benefits: The site has enabled the organisation to catch up with competitors rather than gain a strategic advantage. It has improved customer relations and the ability to provide new and better products and services.

Transactional benefits: The project has been a negative drain in terms of business efficiency, return on assets and employee productivity.

Informational benefits: While information access has been better enabled, its accuracy and usefulness for strategic planning and operational control are woeful.

Overall, the benefits expected have not occurred and the business sponsor believes the implementation of EC has clearly not satisfied the business case.

\section{Customer user satisfaction}

Usability: While the site has an attractive appearance and conveys a sense of competency, it is not easy to navigate and use. 
Information quality: Overall the information outputs are of an acceptable quality.

Sense of confidence and security: The site does not convey a strong feeling of security or confidence that the services will be delivered. However communication with the organisation via the site is easy.

Likelihood to revisit/purchase: Repeat business is possible.

\section{Customer user participation}

No attempt was made to profile potential customers.

Requirements: The establishment of requirements was made by evaluating comparable sites.

Design: A walkthrough of a prototype was performed by potential customers.

Influence: The results of the walkthrough had some influence on the content of the site.

Usability testing: Not done prior to implementation. Performed by customers after implementation

Post-implementation review: Web site logs are evaluated.

\section{Internal user satisfaction}

Usability: Internal users are generally satisfied with their interaction with the system, its appearance and the sense of competency it conveys.

Information quality: There is less satisfaction with the information outputs such as the accuracy, relevance and format of the information.

\section{Internal user participation}

Requirements: Users were interviewed by IS staff and were members of project team developing the functional requirements. They did not develop the information requirements.

Design: Users were not part of the design team, but were included in the process of evaluation and approval of the design prototype.

Testing: Users were involved in both the development of test data, the performance of tests and the approval of tests performed by the IS staff.

Internal users were less satisfied with informational outputs (an aspect they did not participate in during development) than functionality and usability, in which they did participate.

\section{Contingency variables}

System impact: Very little change to organisational structure procedures and work practices.

Resource constraints: Several key resources were constrained: time, relevant expertise in ebusiness development and an appropriate methodology for potential customer participation.

\section{CASE 2. A Major Trading Bank}

The site is a major redevelopment implemented within the last year and was developed in-house. 


\section{Organisational impact}

Strategic benefits: The site has positively aligned the organisation with its stated goals. It has enhanced competitive advantage as well as keeping up with competitors. Has improved customer relations and the ability to provide substantially better products and service to customers.

Transactional benefits: Business efficiency has been very strongly enhanced particularly through faster transaction processing and shortened product cycles.

Informational benefits: These benefits have not accrued. Both information access and information quality (for strategic planning and operational control) have been negatively impacted.

Overall the benefits expected have occurred and the business sponsor believes the implementation of EC has satisfied the business case

\section{Customer user satisfaction}

Usability: The customers rate the site very highly in all usability factors

Information quality: Likewise the customers are very positive about the quality of information displayed such as format, relevance, level of detail and understandability.

Sense of confidence and security: The site promotes a strongly positive sense of safety to complete transactions, security of personal information and confidence in goods/services being delivered.

Likelihood to revisit/purchase: Repeat business is highly likely.

\section{Customer user participation}

Existing site log files were examined to assist profiling of targeted customers, of which more than one group was identified within the target population. Actual customers were then identified within the profile groups to participate in the redevelopment.

Requirements: Targeted customers participated in a range of requirements gathering activities including electronic surveys and focus groups conducted both electronically as well as grouped physically together.

Design: A walkthrough of a prototype was performed by these targeted customers.

Influence: The results of the walkthrough had substantial influence on the site.

Usability testing: Very thoroughly performed by the same group of targeted customers. They performed usability-testing activities both in their usual place of access as well as at the developer's location. They were asked to use the "thinking aloud protocol" ie verbalising their thought $\mathrm{s}$ as they worked, and were recorded while performing the tasks. Metrics collected from the usability testing process were: tasks completed successfully, time taken to complete a task, number of errors made and time spent recovering from errors. The usability testers completed a questionnaire regarding their experiences.

Post-implementation review: Web site logs are evaluated.

\section{Internal user satisfaction}

Usability: Internal users are very satisfied with their interaction with the system, its learnability, navigation and design. Using the system is a positive experience for them. 
Information quality: There is less satisfaction with the information outputs, such as the accuracy, understandability, level of detail and format of the information. However the information is credible, timely and relevant to their work activities.

\section{Internal user participation}

Requirements: Users were members of the project team that developed the system definition and took the entire responsibility for it, including cost justification and project schedule.

Design: Similarly, users were part of the design team, and participated in the process of evaluation and approval of the design prototype.

Testing: Users were not involved in the testing and implementation process.

\section{Contingency variables}

System impact: Given that the system was a redevelopment of an existing site, it is not surprising that there was no change to organisational structure, procedures and work practices.

Resource constraints: Resource constraints were not a hindrance to this project. The substantial in-house IT department had expertise in e-business development, access to potential customers and known methodologies for involving them. Furthermore time and financial resourcing were satisfactory.

\section{CASE 3. A Medium-Sized Car Rental Business}

The site is a major outsourced redevelopment, implemented within the last two years.

\section{Organisational impact}

Strategic benefits: The site has enabled the organisation to catch up with competitors rather than gain a strategic advantage. Customer relations have been improved, as has the ability to provide new and better products and services.

Transactional benefits: The site has provided an improvement in business efficiency with an increased return on financial assets.

Informational benefits: The quality of information and speed of its retrieval and delivery of reports has not improved at all.

Overall the implementation of EC has marginally satisfied the cost and benefit expectations.

\section{Customer user satisfaction}

Usability: The site has an unattractive appearance and an inappropriate design. It is not particularly easy to navigate and use.

Information quality: The information outputs are of an acceptable quality in most respects except the format.

Sense of confidence and security: The feeling of safety of transactions and personal information is negative. There is very low confidence in the organisation as judged by the site.

Likelihood to revisit/purchase: Not likely. 


\section{Customer user participation}

Requirements: No customer-user participation.

Design: No customer-user participation.

Usability testing: No customer-user participation

Post-implementation review: No process to include customer-user participation, but a link is provided for customers to contact the organisation.

\section{Internal user satisfaction}

Usability: Perceived as being excellent.

Information quality: Perceived as being excellent.

\section{Internal user participation}

Requirements: High level of involvement and leadership.

Design: High level of involvement.

Testing: Weak on testing and internal users were not involved.

\section{Contingency variables}

System impact: The EC implementation has caused considerable organisational structure and work practice changes.

Resource constraints: There were some constraints on financial resources and relevant expertise in e-business development.

\section{Discussion}

Table 2 provides a summary of the authors' interpretation of business success, customer-user and internal-user satisfaction for the three organizations studied. The study serves two main objectives. Firstly, it has allowed the testing and validation of the research design. Secondly, it provides a number of insights into the different perspectives of the distinct user groups. The following discussion examines these two features of the research and proposes an outline of future research in the area.

Table 2. Measures of success (scale: +++ very positive, ---very negative)

\begin{tabular}{|l|l|l|l|}
\hline & $\begin{array}{l}\text { Case 1 } \\
\text { Classifieds }\end{array}$ & $\begin{array}{l}\text { Case 2 } \\
\text { Major bank }\end{array}$ & $\begin{array}{l}\text { Case 3 } \\
\text { Car rentals }\end{array}$ \\
\hline Business success & --- & +++ & + \\
\hline Customer-user satisfaction & + & +++ & -- \\
\hline Internal-user satisfaction & ++ & ++ & +++ \\
\hline
\end{tabular}




\section{Testing and Validation of the Research Design}

The results from the three cases show that the research design is robust and a valid mechanism for assessing the significance of user involvement in EC applications development. In each case there was a distinct user group that responded in a knowledgeable way to the questions. Addressing the issues related to the user groups (internal and external) confirms that they are distinct groups with different expectations. Likewise the business sponsor and developer were easily identifiable in each of the organisations. In addition to drawing conclusions regarding user participation, user satisfaction and business success for each organisation, we can compare responses between organisations.

\section{The Implications of the Findings}

In this section we examine the findings of the cases in relation to the broad themes within the questions. For example, questions one to three address resource constraints and are therefore addressed together.

\section{Resource constraints (research questions 1-3)}

Generally resource constraints appeared to impact on the success of the system, from the perspectives of both user satisfaction and business success.

- The major bank developed a strategic EC application and had abundant financial support, time and expertise. This enabled them to involve the customer users and internal users to a relatively high degree. The resulting system was judged to be highly satisfactory by both sets of users and by business sponsor.

- The classified advertising site faced a number of constraints and the resulting system was not very well accepted by both sets of users or seen as a success by the business sponsor.

\section{Impact of the EC System (research questions 4-6)}

- The classified advertising site has not adapted the organisation to a model supporting EC processes, and is having limited success.

- The major bank has already performed substantial organisation structural and procedural change to support the new business model.

- The car rental business has made substantial internal changes but achieved limited success except with internal-users.

\section{Customer-user and internal-user participation (research questions 7-9)}

These research questions appear to indicate a consistent correlation between user participation and user satisfaction. Two of the three cases clearly indicate more participation by internal-users than customer-users.

- The classified advertising site's development made negligible use of customers or potential customers, and customers are only marginally satisfied with it. There was more participation by internal-users and they were more satisfied with the resulting user interface. Interestingly they were not involved in informational requirements and they are dissatisfied with informational outputs. 
- The major bank involved both sets of users to a large extent and both are satisfied with their view of the system.

- The rental car site development had no customer-user participation and this group has reviewed the site very negatively. The internal-users however were highly involved in the process and are particularly satisfied with the system.

\section{System success as measured by user satisfaction and organisation impact (research question 10)}

The major bank shows a clear correlation between business success and user satisfaction. The other two cases are however inconsistent and therefore it is difficult to draw conclusions regarding this question.

\section{Conclusions}

The strength of this study is in the presentation and validation of the research model. All of the research questions have a clear and focussed rationale in relation to assessing the value of user involvement in e-commerce applications development. This research project forms the first part of a comprehensive study. Nonetheless, there are clearly a large number of interesting research issues that have been highlighted and which are worthy of further investigation. For example, it appears that companies are more likely to involve internal users than customers in the design of systems, it could be assumed because of their accessibility. The results presented in this paper are of a qualitative nature and although useful for drawing inferences in relation to the model of user participation a larger quantitative study needs to be conducted to provide statistical reliability.

\section{References}

Barki, H. \& Hartwick, J. (1994). Rethinking the concept of user involvement, and user attitude. MIS Quarterly, 18 (1), 59-79.

Barnes, S.J. \& Vigden, R.T. (n.d.). An integrative approach to the assessment of e-commerce. Unpublished manuscript.

Baroudi, J.J., Olson, M.H., \& Ives B. (1986). An empirical study of the impact of user involvement on system usage and information satisfaction. Communications of the ACM, 29 (3), 232-238.

Baroudi, J.J. \& Orlikowski, W.J. (1988). A short-form measure of user satisfaction: A psychometric evaluation and notes on use. Journal of MIS, 4 (4), 44-59.

Bussen, W.S. \& Myers M.D. (1997). Executive information systems failure: A New Zealand case study. PACIS '97, Brisbane, Information systems Management Research Concentration, QUT, Australia.

Cote, J.A., \& Buckley, M.R. (1987, August). Estimating trait, method, and error variance: Generalizing across 70 construct validation studies. Journal of Marketing Research, 24.

DeLone, W.H. \& McLean, E.R. (1992). Information systems success: The quest for the dependent variable. Information Systems Research, 3 (1), 60-95.

Doll, W.J. (1987). Encouraging user management participation in systems design. Information and Management, 13 (1), 25-32.

Doll, W.J. \& Torkzadeh, G. (1989). A discrepancy model of end-user computing involvement. Management Science, 35 (10), 1151-1171.

Doll, W.J. \& Torkzedah, G. (1990). The measurement of end-user software involvement. Omega, 18(4), 399-406. 
Foster, S.T. (Jr.) \& Franz, C.R. (1999). User involvement during information systems development: A comparison of analyst and user perceptions of system acceptance. Journal of Engineering and Technology Management, 16, 329-348.

Franz, C.R. \& Robey, D. (1986). Organisational context, user involvement, and the usefulness of information systems. Decision Sciences, 17 (3), 329-356.

Fraternali, P. (1999). Tools and approaches for developing data-intensive web applications: a survey. ACM Computing Surveys, 31 (3), 227-263.

Garceau, L., Jancura, E., \& Kneiss, J. (1993). Object oriented analysis and design: A new approach to systems development. Journal of Systems Management, 44, 25-33.

Hunton, J.E. \& Beeler, J.D. (1997, December). Effects of user participation in systems development: A longitudinal experiment. MIS Quarterly, pp. 359-383.

Ives, B. \& Olsen, M.H. (1984). User involvement and MIS research: A review of research, Management Science, 30 (5), 586-603.

Land, F. \& Hirschheim, R. (1983). Participative systems design: Rationale, tools and techniques. Journal of Applied Systems Analysis, 10, 91-107.

Loiacono, E.T., Watson, R.T. \& Goodhue, D.L. (n.d.). WebQual ${ }^{T M}$ : A measure of web site quality. Unpublished manuscript.

Mirani, R. \& Lederer, A.L. (1998). An instrument for assessing the organizational benefits of IS projects. Decision Sciences, 29 (4), 803-838.

McKeen, J.D. \& Guimarares, T. (1997). Successful strategies for user participation in systems development. Journal of Management Information systems, 14 (2), 133-150.

McKeen, J.D., Guimaraes T., \& Wetherbe, J.C. (1994, December). The relationship between user participation and user satisfaction: An investigation of four contingency factors. MIS Quarterly, pp. 427-451.

Olson, M.H. \& Ives, B. (1980). Measuring user involvement in information systems development. Proceedings of the International Conference on Information Systems, Philadelphia, PA.

Porter, M.E. (2001, March). Strategy and the Internet. Harvard Business Review, pp. 63-78.

Powers, R.F. \& Dickson, G.W. (1973). MIS project management: myths, opinions and reality. California Management Review, 15 (3), 147-156.

Schwarz, M. (2001, Feb-March). The care and keeping of online customers. Information Age, pp. 61-62.

Silverman, D. (2000). Doing qualitative research. A practical handbook. London: Sage Publications.

Tait, P. \& Vessey, I. (1988). The effect of user involvement on system success. MIS Quarterly, 12 (1), 90107.

Terry. J.E. \& Standing, C. (2001). User involvement in E-Commerce systems development. Proceedings of the Twelfth Australasian Conference on Information Systems, Coffs Harbour, pp. 671-678.

Yin, R. (1994). Case study research; design and methods ( $2^{\text {nd }}$ ed.). Sage.

Yourdon, E. (2000, August 21). Success in e-projects. Computerworld. 


\section{Biographies}

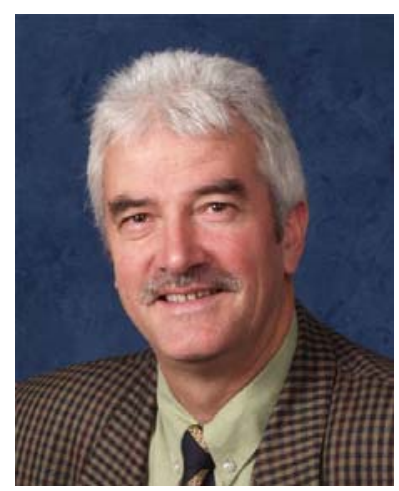

Julian Terry is a lecturer is Computer Science at Edith Cowan University in Australia. He is currently completing his $\mathrm{PhD}$ on software development methodologies for e-commerce systems. He teaches in Software Engineering and has published in the Australian Computer Journal and the International Journal of e-Business Management.

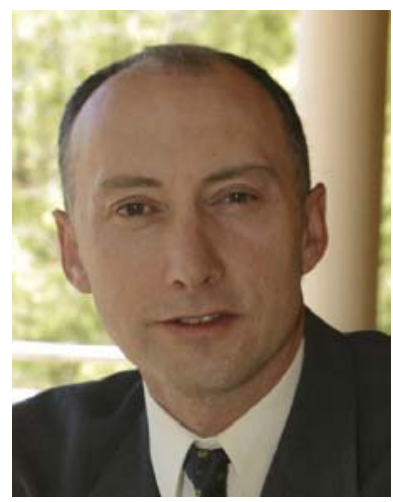

Dr Craig Standing is Professor of Strategic Information Management at Edith Cowan University. He received his $\mathrm{PhD}$ from the University of Western Australia in 1997. His research specializes in electronic markets, e-commerce adoption and assimilation. He has published widely in Information Systems journals including Journal of Electronic Markets, IS Frontiers and the Journal of Information and Software Technology. 